\title{
LA OTRA VOZ: PERSONA Y PERSONAJE \\ EN CUATRO POETAS VENEZOLANOS DE LA ÚLTIMA GENERACIÓN
}

POR

\author{
Rafael Castillo Zapata
}

Después de una compleja década de nuevas búsquedas en el mapa de la expresión realista (exhibición de la propia intimidad contextualizada en un mundo recreado lleno de marcas sociales y culturales inmediatas, retrato moroso y reflexivo de la vida urbana, inclinación gozosa por los ritmos y léxicos del habla cotidiana, entre otras cosas), la poesía venezolana de los noventa, sin poder renunciar a los valiosos hallazgos y a las conquistas de la práctica poética anterior, comienza a dar interesantes señales de un cierto cambio de rumbo, anunciado, lógicamente, en muchos de los poemas y de los libros escritos, sobre todo, hacia finales de los años ochenta.

Dos críticos inteligentes, poetas ellos mismos, es decir, a la vez jueces y partes de un proceso de creación y valoración que funciona todavía, en Venezuela, como una suerte de máquina cerrada, en buena medida endogámica, han tratado de describir la orientación de este nuevo rumbo. Javier Lasarte, por ejemplo, ha señalado, entre otras claves, la del supuesto agotamiento de la reflexión sobre el propio espacio urbano y cotidiano, "como si fuese necesario enmascararlo o sustituirlo por cierto cosmopolitismo excéntrico, o fuese preciso diseñar otros espacios para reconocer en ellos la distancia, la inaccesibilidad y el desencuentro". ${ }^{1}$ Me interesa especialmente esta acotación en la perspectiva del presente artículo, puesto que mi interés se concentra, en parte, en la tarea de describir la propensión de ciertos poetas recientes por explorar y recrear paisajes y personajes exóticos, siguiendo, en algunos casos, la huella concreta de referentes históricos o geográficos existentes y, en otros, simplemente imaginándolos, con la intención de producir lo que pudiéramos llamar un "efecto de alteridad" o extrañación.

Leonardo Padrón, el otro crítico, por su parte, habría detectado, en cierta porción de la poesía venezolana de finales de los ochenta, la creciente tendencia hacia una suerte de retorización de los recursos realistas, indicando así la aparición de un uso rápidamente epigonal de esos recursos y, en consecuencia, un evidente desgaste de la efectividad expresiva o estilística de los mismos. ${ }^{2}$ Esto es algo que también me interesa destacar en relación con mis propósitos actuales: la creciente modificación y readaptación de los recursos realistas (referentes concretos, marcaje léxical y toponímico, datación histórica,

\footnotetext{
1 Javier Lasarte, Cuarenta poetas se balancean (Caracas: Fundarte, 1991).

${ }^{2}$ Leonardo Padrón, Crónicas de la vigilia (Caracas: Academia de la Historia, 1990).
} 
reproducción de hablas regionales, exploración de la cotidianidad) en los cuatro poetas que considero. Pues no se trata, en realidad, como lo señalo en el párrafo inicial, de una ruptura con semejante retórica, sino de una reformulación de sus principios a la luz de nuevas estrategias, entre las cuales, me parece necesario destacar tres: 1) la exploración histórica y documental para diseñar el poema, recurriendo a elementos formales y temáticos proporcionados por la tradición de la lengua o de la cultura a la que pertenecen, regional o globalmente; 2) la recuperación de cierto carácter lúdico de la actividad poética, sin otra finalidad que el juego mismo, hecho evidente, por ejemplo, en el empleo efectivo de la parodia; y 3) la creciente dramatización de la escritura, es decir, la tendencia a configurar el poema no ya como el producto de una confesión directa de la propia experiencia, real o imaginada, sino de la expresión de esa misma experiencia a través de máscaras poéticas y voces simuladas. Estas tres estrategias se vinculan, a mi modo de ver, de una manera bastante estrecha. La exploración del pasado histórico o de los orígenes de la literatura escrita en la propia lengua, responde, en parte, a la necesidad señalada por Lasarte de escapar a la tal vez ya, para el momento indicado, saturada fijación sobre la realidad inmediata y al intento de buscar nuevos moldes expresivos distintos a los de la coloquialidad, por ejemplo. Lo cual, me parece, está ligado, al mismo tiempo, con la necesidad de asumir personalidades distintas en el poema y recurrir, por ello, al empleo de máscaras y voces apócrifas para encubrir el origen de la enunciación y escapar a las tentaciones de la identificación biográfica, por un lado, $\mathrm{y}$, por el otro, con la tendencia lúdica a la parodia, entendida como burla de los principios de autoridad y de identidad aplicable tanto al mismo poeta como a otros sujetos, históricos o literarios. De este modo, algunos poetas venezolanos de la última generación estarían intentando, cada vez con mayor destreza, recuperar ciertos recursos tradicionales, pero quizás poco utilizados en la poética anterior, o solamente apuntados en ella, como los del monólogo dramático, por ejemplo, para exponer sus contenidos anímicos o sensuales, sus deseos, sus frustraciones, sus sueños o su memoria en el poema. Y es este fenómeno en su conjunto el que trataremos, precisamente, de describir aproximándonos a esos cuatro poetas, a mi modo de ver, representativos de un proceso que incluye - y eventualmente incluirá en un futuro inmediato- a un número más sustantivo de escritores.

Como bien lo apuntaba Jaime Gil de Biedma, "toda la poesía es una forma de inventar una identidad". En tal sentido, todo poema es la elaboración en clave ficticia de una experiencia de vida y el protagonista de esa experiencia es, en mayor o menor grado, un "personaje inventado", pues, ciertamente, "cuando un poeta habla en un poema, quizá no hable como personaje imaginario, pero como personaje imaginado siempre". ${ }^{3}$ T. S. Eliot, por su parte, ha identificado, en un ensayo ya clásico, "las tres voces" caracterizadoras de toda enunciación lírica, atendiendo al destino de esa enunciación: el poeta habla consigo mismo, el poeta habla a una audiencia, el poeta crea un personaje que habla a otros personajes. ${ }^{4} \quad \mathrm{Y}$ es precisamente a la segunda voz eliotiana, a esa dicción cuasi-

\footnotetext{
${ }^{3}$ Jaime Gil de Biedma, "Sobre el hábito de la literatura como vicio de la mente y otras ociosidades", El pie de la letra (Barcelona: Crítica, 1984).

${ }^{4}$ T. S. Eliot, "The three voices of poetry", On Poetry and Poets (Nueva York: Noonday, 1961)

96. "The first voice is the voice of the poet talking to himself —or to nobody. The second is the
} 
dramática ${ }^{5}$ vinculada estrechamente con el concepto de "personaje inventado" y "personaje imaginado" expuesto por Gil de Biedma, la que va a servirme de palanca para aproximarme al trabajo de enmascaramiento y simulación que caracteriza a los cuatro poemarios elegidos. Esa segunda voz eliotiana adquiere una expresión paradigmática en el llamado "monólogo dramático", ${ }^{6}$ en el cual el poeta, por así decirlo, no cede la enunciación a un personaje que tendría una voz propia, intransferible y reconocible, sino que asume la voz de otros para hablar de sí o desde su propio punto de vista, es decir adquiere una máscara y habla tras ella, a través de ella, como si fuera otro, pero sin dejar de hacer evidente que el origen de esa voz simulada es él mismo. ${ }^{7}$ Muestras ejemplares de semejante procedimiento pueden encontrarse, obviamente, en Browning, o en Pound, cuyo Personae (1909) es un modelo en tal sentido. ${ }^{8}$ En Fatal (1989), de Alicia Torres; Toledana (1992), de Sonia Chocrón; Cantigas (1990), de Harry Almela, y Diario de John Robertson (1990), de Blanca Strepponi, creo ver, precisamente, versiones y reelaboraciones de este modelo, poemarios en los cuales la creación de personajes permanece en el nivel de la máscara y del proceso que el propio Eliot llama "ventriloquismo", " todo ello encaminado, como lo advertimos al comienzo, a producir un "efecto de alteridad", efecto mediante el cual el poeta se extraña de sí mismo asumiendo personalidades anacrónicas o ficticias, simulando lenguajes arcaicos, situando sus representaciones en escenarios exóticos. Semejante recurrir a la máscara y a la simulación de una voz otra - personaje histórico, personaje de la ficción, personaje inventado - para dirigirse a una determinada audiencia, presenta en estos cuatro libros una relevancia fundamental: no remite tan sólo a los procesos típicos de ficcionalización propios de todo mecanismo literario, sino que se refiere a una búsqueda deliberada y específica de marcar distancia, a través de la máscara, de la voz representada y del escenario exótico, de una probable, y a veces previsible, identificación entre el poeta y lo que el poema expresa. Este énfasis señala, a mi modo de ver, un deseo, consciente o inconsciente, de estos poetas por apartarse de la tendencia confesional de parte de la poesía de orientación

voice of the poet addressing an audience, whether large or small. The third is the voice of the poet when he attempts to create a dramatic character speaking in verse; when he is saying, not what he would say in his own person, but only what he can say within the limits of one imaginary character addressing another imaginary character".

${ }^{5}$ T. S. Eliot 96; “ $\ldots$ the distinction between the poet addressing other people in either his own voice or assumed voice, and the poet inventing speech in which imaginary characters address each other, points to the problem of the difference between dramatic, quasi-dramatic, and nondramatic verse".

${ }^{6}$ T. S. Eliot 102; "What we normally hear, in fact, in the dramatic monologue, is the voice of the poet, who has put on the costume and make-up either of some historical character, or of one out of fiction".

${ }^{7}$ T. S. Eliot 104; "The poet, speaking, as Browning does, in his own voice, cannot bring a character to life: he can only mimic a character otherwise known to us".

${ }^{8}$ T. S. Eliot 103-104; "It was Browning's greatest disciple, Mr. Ezra Pound, who adopted the term 'persona' to indicate the several historical character through whom he spoke: and the term is just".

${ }^{9}$ T. S. Eliot 110; "That may be a very different thing from the ventriloquism which makes the character only a mouthpiece for the author's ideas or sentiments". 
realista inmediatamente anterior, tendencia que sugería una relación más directa entre el poeta y las voces asumidas en el poema, dada la carga de anclajes históricos, toponímicos y léxicos que lo caracterizaba, llegando hasta los límites, en algunos casos, de la transparencia biográfica. Reaccionando contra esta tendencia, algunos poetas de finales de los ochenta y principio de los noventa, como los mencionados, están tendiendo a una exposición cada vez más mediada, interferida, dramatizada de sus propias experiencias. ${ }^{10}$

En cada uno de los libros considerados, un aspecto específico de esa reacción adquiere carácter dominante, sin desvincularse, como veremos, del resto. En Fatal, ${ }^{11}$ por ejemplo, lo relevante parece ser, precisamente, el recurso del mónologo dramático, la sucesiva aparición de máscaras femeninas a través de las cuales una sola voz parlante se modula simulando registros diferenciados. Una misma tonalidad enunciativa, un aparato léxico reiterado a lo largo del poemario, nos hablan de un centro emisor que se bifurca para adaptarse a las intenciones del proyecto ideológico que caracteriza al libro: recontar la historia de la mujer a partir de las versiones, reversiones e inversiones del prototipo literario de la femme fatale. Para hacerlo, Torres recurre a la selección de personajes y situaciones históricas que se identifican por su carácter exótico, marcado en el texto por rasgos toponímicos y léxicos.

En Toledana,${ }^{12}$ el monólogo dramático se reduce a la enunciación proyectada desde una única máscara, la del personaje histórico de la amante judía del rey Alfonso VIII de Castilla, quien relata su trágica aventura desarrollada en pleno siglo XII. Los intentos de Chocrón por marcar esa voz con los elementos característicos del habla medieval hispánica durante la vigencia de la extraordinaria confluencia cultural mudéjar son la muestra de una interesante exploración literaria en el pasado para encontrar nuevos recursos de enunciación, utilizándolos mediante procesos paródicos y no de mera transcripción o reproducción. Aquí, como en Fatal, el núcleo temático es la experiencia femenina del amor.

En Cantigas $^{13}$ los juegos paródicos de la autoría, en la primera parte del libro, nos hacen recordar todos los efectos de suplantación de la identidad comunes a cierto tramo de la tradición literaria occidental, incluyendo las simulaciones apócrifas, seudonómicas o heteronómicas, todo ello apelando al proceso de enunciación a través de diversas máscaras. En la segunda parte, que da título a todo el conjunto, Almela se impone el reto de simular la voz de una mujer para expresar la pasión amorosa. Y elige una máscara ambigua, sin nombre, identificable por diversas marcas explícitas o implícitas. Veremos aquí, como en Toledana, el empleo de un recurso erudito: la presencia de la "cantiga de amigo" galaicoportuguesa como soporte formal tradicional de una voz que habla, evidentemente, desde la contemporaneidad, para expresar contenidos que ironizan la propia experiencia amorosa.

\footnotetext{
${ }^{10}$ Parafraseando a John Crowe Ramson, dice Antonio Carreño: "el drama es un excelente símbolo de la poesía. El poeta no habla en su nombre, sino a través del personaje que se da por supuesto en el poema. El poeta impone su máscara a través del lenguaje poético, y en cada situación se endosa un disfraz", La dialéctica de la identidad en la poesía contemporánea (Madrid: Gredos, 1982) 24.

${ }^{11}$ Alicia Torres, Fatal (Caracas: Fundarte, 1989).

${ }^{12}$ Sonia Chocrón, Toledana (Caracas: Monte Ávila Editores, 1992).

${ }^{13}$ Harry Almela, Cantigas (Caracas: Fundarte, 1990).
} 
Una vez más, como en los otros dos libros mencionados, el tema amoroso surge como elemento temático polarizante y configurador.

Finalmente, en Diario de John Robertson, ${ }^{14}$ Strepponi recurre a un documento histórico para extraer de allí los elementos de su proyecto lírico. Se trata del auténtico diario de un médico escocés, cirujano del ejército de Bolívar, escrito en Venezuela entre 1818 y 1820 y publicado en Londres en 1822. Strepponi asume la máscara de Robertson para reflexionar a través de ella acerca de la experiencia terrible del mal en general y de esa expresión suya particular que es la muerte. La propia vicisitud biográfica de Robertson registrada en el diario -el infierno de la guerra en un mundo desconocido y salvaje, seductor y maléficole sirve de manera perfecta para unos propósitos que están, evidentemente, más allá del personaje histórico. La propia textura discursiva del poemario deja ver claramente que ha habido un trabajo de parodización con respecto al documento catalizador de la escritura: el diario funcionaría, así, no sólo como "prototexto", sino como "pretexto" del poemario, más allá de las otras relaciones intertextuales que pueden, de hecho, establecerse.

Estas rápidas descripciones sintéticas, antes de entrar a explorar más detenidamente cada uno de los libros, nos ofrecen de antemano varios indicios: primero, la coincidencia en tres de los poemarios al elegir una reflexión sobre el tema amoroso como centro de su maquinaria verbal, asumiendo todos un punto de vista y un punto de enunciación femeninos para hablar; segundo, el recurso a la máscara construida a partir de personajes históricos, de la realidad o de la literatura; tercero, la simulación de la voz en clave erudita y paródica al mismo tiempo: investigación de las fuentes originarias del habla (literatura medieval, diario decimonónico) para reproducirlas de modo infiel, traicionándolas al "traducirlas"; cuarto, la evidente dependencia intertextual que presentan. Todos estos indicios, en los que están, sin duda, implícitas las tres estrategias mencionadas más arriba, nos servirán de punto de partida para calar más a fondo en cada uno de los textos seleccionados.

La intencionalidad implícita y explícita de Fatal está marcada por esa primera y fundamental clave que es, obviamente, el título. La mención de lo "fatal" a secas, así, sin mediación, sin determinación y sin matices, promueve una lectura del libro en la órbita de una "fatalidad" en la que se mezclan, ya veremos, lo irrevocable del fatum y la voluptuosidad considerada como una experiencia límite, lindante con la muerte, manifestación del mal. Esta clave primera está reforzada por los diversos epígrafes que introducen al libro mismo en su conjunto y a cada una de las secciones que lo componen. No en balde, después del título, el poemario nos pone en el camino un fragmento de Sylvia Plath que dice: "something beautiful but annihilating". En efecto, el libro va a jugarse en el sentido de esa relación - $\tan$ conscientemente explorada por el romanticismo, el simbolismo y el modernismo- que asocia la belleza con una experiencia amenazadora, terrible, destructiva, demoníaca . La primera sección, por su parte, recurre a Sade para marcar sus dominios: "No hay voluptuosidad sin crimen", invitándonos a leer la representación que a partir de allí comienza en el sentido señalado por el vínculo entre erotismo y transgresión que el autor de Justine nos propone, lo cual no hace sino apoyar la dirección indicada por el título y el epígrafe general. El resto de los epígrafes - que no citamos por razones de espacio-

${ }^{14}$ Blanca Strepponi, Diario de John Robertson (Caracas: Pequeña Venecia, 1990). 
colaboran también en ese mismo sentido. Si ahora repasamos rápidamente los títulos de algunos poemas: "Circe", "Salomé", "Sacerdotisa", "Sirena", "Helena", "Clitemnestra", "Esclava egipcia", "Arachné", "Mora”, vemos que el aparato de claves se amplía, se afina, nos acerca cada vez más al modelo de lectura que Fatal nos está proponiendo y nos permite, de entrada, anticipar la materia que en él se teje y se expone. Así, podemos decir sin más preámbulos que el libro de Alicia Torres gira en torno a varios ejes temáticos: la mujer, el erotismo, los referentes mitológicos o legendarios, lo exótico que se construye a partir de ellos. La figura de la femme fatale decimonónica y sus anticipaciones y derivaciones (sirena, maga, hechicera, vampiresa, devoradora de hombres, prostituta) sirve como rostro común, por así decirlo, a todas las sucesivas personificaciones femeninas que, en el poemario entero, están dirigidas a crear una imagen reivindicadora de la mujer, recurriendo para ello a la exploración y representación del plano de su experiencia de lo erótico, zona en la cual se nos invita a reconocer la supremacía y el dominio de la mujer sobre el hombre, en ese terreno de juego en el que ella - sensualidad, inteligencia, astucia, de por medio-llevaría evidente ventaja, como lo pone en evidencia el tono retador de "Circe":

Tengo un afecto desmedido

por el cambio.

Un poco de arte,

un hechizo anticuado,

todavía conmueven pesos muertos.

No me hurtes la mirada, hipócrita, en mi casa todo te delata

y haces mal en creerte a salvo.

Con la mano izquierda

convierto en turbulencia

la placidez del aire que te ronda.

Con la mano derecha

reescribo el tedio prematuro

que se lee en tu frente.

Me deslizo íntegra

por la vertiente de tu deseo más oculto

$y$ te pongo en evidencia, Fiera,

te despojo del ridículo disfraz,

dejándote garras y pelambre recia,

descubriéndote, como el envés de un guante,

la salvaje alegría

de no ser inocente.

$\mathrm{Y}$ ahora lánzate

sobre el rastro de sangre que te muestro.

Desciende al infierno que sin saber

buscabas. ${ }^{15}$

${ }^{15}$ Alicia Torres 19-20. 
Buena parte del carácter vindicatorio de esta imagen de la mujer que el libro propone, se sostiene, precisamente, en la utilización de personajes femeninos emblemáticamente transgresores, dominadores o triunfadores: Circe sometiendo con sus hechizos a Odiseo, Judith degollando a Holofernes, Magdalena escupiendo la mano de Cristo, todo lo cual contribuye a proporcionar una imagen de la sexualidad y de la sensualidad femeninas desvinculada del orden de las estrecheces y rutinas cotidianas, opuesta a una concepción meramente reproductiva o servicial de la actividad erótica.

En todo ello es evidente que Torres ha querido escapar a un modo de representación de la experiencia femenina del erotismo que tendiera a inclinarse demasiado hacia la identificación confesional, hacia la aparente transparencia autobiográfica, por un lado, y ha optado, al mismo tiempo, por escenificar esa experiencia en un ámbito distinto al doméstico, cotidiano y urbano, por el otro. Para hacerlo se ha valido del doble recurso del enmascaramiento y de la simulación de la voz para la expresión de sus contenidos. Máscara y voz simulada se complementan con otro procedimiento: me refiero al referente exótico que le sirve de soporte material y de telón de fondo a su mundo representado, marcado constantemente a nivel toponímico y lexical: "obsidiana", "Samoa", "enagua de bramante", "esencia de heliotropo", "malaquita", "lapislázuli", "cáñamo de la lejana Cachemira", "címbalos y flautas", "ónix", "perfumes abisinios", "la arena roja de Henen-nesut".

Estamos, entonces, frente a una mujer que nos habla de la fatalidad de su existencia a través de diferentes máscaras en un escenario lleno de ingredientes exuberantes o legendarios, distantes en el tiempo y en el espacio. De este modo, por un lado, en cada poema de Fatal habla una misma experiencia fragmentada; cada poema es una representación más de esa experiencia femenina expuesta detrás de una máscara, de una "persona", y de la voz proyectada desde ella; por el otro, cada puesta en escena se encuentra revestida por elementos de extranamiento geográfico e histórico.

En efecto, lo verdaderamente funcional en la apuesta expresiva de Fatal es la máscara a través de la cual se habla: la voz que surge mediante este procedimiento no es propiamente una voz simulada, no hay marcas que caractericen y diferencien, por ejemplo, la voz de Circe de la de Frida Kahlo; se trata de una misma entonación y de un mismo registro lexical levemente deformados por el paso a través de la máscara, cuya marca fundamental es, sin duda, el título: creemos distinguir la voz de Circe y de la de Kahlo por la influencia que el anclaje semántico del encabezamiento ejerce sobre nosotros, como lectores y "auditores" de cada una de esas voces.

Siendo así efectivamente, todo esto no hace sino afianzar la intencionalidad expuesta por la titulación y los epígrafes. Tanto los personajes históricos - Judith, Salomé, Frida Kahlo- como los incorporados directamente de la mitología o de la leyenda clásicas Parca, Circe, Helena, Penélope, Ifigenia - o como los meramente inventados o diseñados a partir de prototipos culturales - Sacerdotisa, Esclava Egipcia, Macabea - contribuyen a fijar una imagen "fatal" de la mujer, en los diversos sentidos marcados al principio, sintetizados de manera ejemplar en el poema que, no en balde, le da el nombre al libro:

Dicen

que en las selvas de Samoa

hay una planta

hermosa 


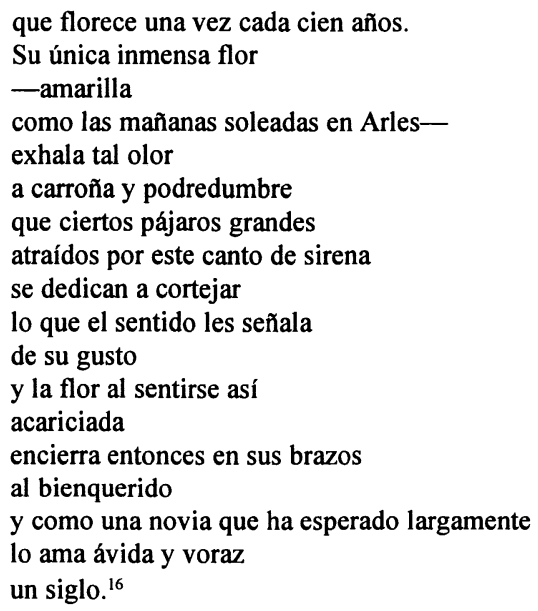

Firmada por la autora, una breve nota al inicio de Toledana pone inmediatamente en la pista del mundo representado al que nos convoca el libro: "Hay una leyenda que relata los amores de Raquel, judía muy fermosa y toledana, con el Rey Alfonso VIII de Castilla. Se dice que fue tan grande pasión que los vasallos del Monarca a Raquel le dieron muerte por razones de estado". La inscripción histórica, entonces, se marca desde el principio: se nos invita a asistir a la representación fabulada de una aventura con enraizamiento real en la época de esplendor de la cultura mudéjar, expresión de la productiva convivencia entre árabes, judíos y cristianos durante la Edad Media española. Y, en efecto, los poemas están orientados a ofrecernos la imagen de este personaje, a la vez histórico y literario - puesto que ha sido objeto de interpretaciones anteriores e impregnado, por eso, de elementos legendarios ${ }^{17}$ - a través de una serie de recursos de simulación. En este caso, hay una sola máscara y una misma voz proyectándose a través de ella a lo largo del poemario. Pero a diferencia de lo que ocurre en Fatal donde, como ya vimos, la diversidad de máscaras no corresponde a una misma diversidad de voces diferenciadas, marcadas con los rasgos especificadores de una identidad, en Toledana hay un intento deliberado por marcar esa voz con elementos que inclinan a leer sus expresiones como emitidas realmente por una judía del siglo XII, en tiempos de Alfonso VIII, Rey de Castilla. El tema amoroso vuelve a hacer aparición aquí, pero en el orden fijado por un proyecto completamente distinto, cuyos modelos expresivos y conceptuales se encuentran en la literatura medieval, trovadoresca, o en textos fundamentales del imaginario amoroso occidental como el Cantar de los cantares. Siguiendo una orientación distinta a la propuesta en Fatal para desarrollar

\footnotetext{
16 Alicia Torres 13.

${ }^{17}$ El personaje de la judía toledana Raquel ha sido objeto de una importante atención por parte de los escritores españoles, desde Lope de Vega en el siglo XVII (Las paces de los reyes y la judía de Toledo) hasta García de la Huerta en 1778 ( $L a$ Raquel), pasando por Mira de Amescua ( $L a$ desdichada Raquel), Diamante (La judía de Toledo) y Ulloa Pereira (Raquel).
} 
el mismo aspecto - la polémica sobre la condición femenina dinamizaba allí, como vimos, la proliferación de máscaras caracterizadoras para modular la voz a través de ellas y exponer argumentos reivindicatorios diversificados - en Toledana la estrategia formal de la simulación se dedica a mostrar una sola presencia femenina sin incluir, en la construcción de su personalidad, ningún elemento de carácter crítico, asumiendo, por el contrario, la voz característica que habla en las "jarchas" arábigo-andaluzas o en las "cantigas de amigo" de la tradición popular galaico-portuguesa. ${ }^{18}$ No habría, de este modo, una relectura cuestionadora, a nivel temático, de la minusvalía y la carencia amorosas de la mujer representada en ese tipo específico de poesía medieval. En cambio, podemos verificar en Toledana la presencia de una reinterpretación paródica, bajo la forma de una cita infiel o parcial, de la estructura métrica y del léxico característico de esa misma práctica poética.

La propia nota inicial ya nos ofrece algunas claves de los procedimientos empleados por Chocrón para construir lo que hemos llamado el "efecto de alteridad". Como puede verse, utiliza allí elementos léxicos y sintácticos que nos indican un primer método, el de la interpolación orientada a simular lo arcaico: "fermosa", "fue tan grande pasión". Una rápida hojeada del libro nos pondrá en claro la presencia de otro método empleado de forma simultánea: la utilización peculiar de estructuras métricas —rítmicas y eufónicaspropias de la literatura hispánica medieval. Es precisamente mediante inclusiones de palabras de este tipo y de inversiones sintácticas semejantes articuladas en formas estróficas que remiten a la tradición popular, como se procede, en el poemario, al intento de construcción de una voz alterna, diferenciada.

Las interpolaciones de expresiones y nombres arcaicos abundan en medio del vocabulario de un castellano corriente y contemporáneo: "hecha a la mesma", "expulsos", "por do andan reyes y sabios", "mancebo", "galanura", "compaña", "destas grandes maravillas", "como está de los reyes hacer" y otros muchos. Tienen especial relevancia en este sentido las palabras de origen árabe: "ataujía", "aljama", "alacena", "anafe". El empleo del verbo haber en el sentido de "tener" destaca en algunos casos: "He dos mirlos muy despiertos por mirada", "Soy yo quien ha capullos reventando"; lo mismo que el empleo del adjetivo posesivo determinado por el artículo: "como éste el mi bastidor", "los mi ojos en desvelo", "que el mi oído"; o las inversiones sintácticas: "ni sabido descifrar del firmamento cuáles astros", entre otros. La inclusión de este tipo de elementos del habla medieval en el tejido del castellano contemporáneo no siempre logran sostener la verosimilitud del simulacro. En la mayoría de los casos asistimos, en cambio, a una simultaneidad confusa de ambos registros.

Sacrificar fundiéndose en las cosas ese es el pacto de la muerte con la vida la vela sucumbiendo ante la llama

18 Véase A. D. Deyerrnond, La Edad Media (Historia de la literatura española I) (Barcelona: Ariel, 1982) 30 y 40. "Pertenecen casi todas las jarchas a un género de poesía de amor femenino: espresan el anhelo de una doncella en la ausencia de su amante, el dolor de su partida o infidelidad, o-menos frecuentemente- el júbilo ante su presencia”; y “... sólo la mujer habla, o lo hace la primera, en las cantigas de amigo ...". 


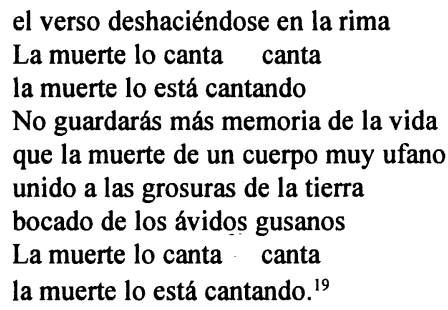

Como lo deja ver este ejemplo, el otro importante recurso simulatorio utilizado corresponde a la manipulación eurrítmica y eufónica de los textos. Chocrón se vale, por un lado, de algunos elementos característicos de la estructuración estrófica tradicional, como la anáfora o el estribillo, para inscribir la voz que habla en los poemas en un escenario ancrónico. Pero los modelos originales están desmontados y citados de manera parcial o irregular en el contexto de una estructuración enteremente anárquica de los versos, en los cuales no podemos describir continuidades rítmicas de ninguna especie, ni, por lo tanto, ninguna repartición medida de las cantidades sonoras. El poemario, entonces, se sirve del modelo de la versificación tradicional para traicionarlo, tomando de él sólo algunos elementos aislados para organizarlos caprichosamente, parodiando, en algunos casos, formas típicas como la agrupación y reiteración paralelística de los versos. De la misma forma, cuando Chocrón apela al recurso de la rima para producir los efectos propuestos, lo utiliza de modo irregular y episódico: un mismo poema puede funcionar, así, como un mosaico de versos en el que, algunos de ellos, están relacionadas por algún tipo de consonancia o asonancia final, y el resto se encuentra desprovisto de cualquier estructura de relación.

Todo ello nos puede llevar a pensar que Chocrón no se ha propuesto reconstruir el personaje histórico y literario de Raquel ciñéndose a ningún tipo de fidelidad documental o verbal, siendo que la vinculación erudita con los textos y las fuentes que preceden a su escritura aparece ironizada. Simplemente se ha servido del personaje para formalizar - a través de la máscara que, de ese modo, se proporcionaba - sus propias reflexiones acerca de la experiencia amorosa, jugando con los elementos caracterizadores del modelo - su pensamiento, su voz- y haciendo, entonces, de la simulación misma una parodia, burlándose del propio universo representado y de las intenciones que parecen animar al poemario.

Cantigas se abre, en su primera parte, titulada "Ventana de emergencia", con una testamento apócrifo de Plinio, el Viejo (que en el texto aparece firmando el documento como "Plinio, el Antiguo"), en el cual la mezcla anacrónica de diversos elementos y el tono irónico de la composición nos dan ya consistentes pistas para entender el proyecto que anima no sólo a esa sección peculiar, sino al libro en su conjunto: "No poseo bienes de fortuna. Mi única riqueza consiste en una biblioteca y en dos o tres túnicas que me fueron otorgadas para ejercer mis cargos públicos.[/] De entre mis libros sobre Historia Natural

\footnotetext{
${ }^{19}$ Sonia Chocrón 69.
} 
(que servirán de códice a un ciego de cabellos argentinos), quiero que éste, titulado Ventana de emergencia, sea entregado a Adrianus Aelius Imperator. Ciudadano de griega cultura, vivirá en una ciudad fundada por los hispanos allende el mar, la cual llevará el nombre de sus nativos. [/] Políglota y amante del cine, Adrianus dará a este libro el mejor uso. [/] Es mi voluntad."

Como puede apreciarse, hay aquí, de entrada, buenos elementos caracterizadores: la atmósfera humorística provocada por el juego paródico, las alusiones perifrásticas o elípticas, las anticipaciones anacrónicas, que encontraremos, combinados con otros, a lo largo del poemario. "Ventana de emergencia", su primera parte, vendría a ser entonces el testamento del fingido Plinio, y, en tal sentido, se trataría no de un testamento en el modo usual o previsible de un documento de tal naturaleza, sino de un testamento hecho de poemas, muchos de los cuales no pueden atribuirse - y de hecho son enunciados por voces con máscaras distintas - al personaje apócrifo. Así, Plinio, una máscara, se fragmenta, a su vez, en otras máscaras. La pluralidad y diversidad de máscaras y voces que pueblan esta sección del libro es, en consecuencia, realmente llamativa y los logros de Almela en la tarea de producir el "efecto de alteridad" son, en algunos casos, impecables. Hay que tomar en cuenta, además, que el "efecto de alteridad" está logrado a partir de la ironía y de la glosa infiel: no hay ningún intento por marcar el texto con procedimientos arcaicos, como en el caso de Toledana, que simularían lo antiguo de determinados textos. Un buen ejemplo de esto es el poema titulado "Manuscrito hallado en el puerto de Nápoles" donde escuchamos, evidentemente, la voz de Plinio:

Yo, que he sido fiel al linaje de Vespasiano,

Comandante de tropas en la Germania, Procónsul

en la Hispania y en las Galias;

yo, que me he servido del rudo dialecto

de mi tiempo para hablar de astros

y de plantas, celebrando tierras y costumbres;

yo, que descubrí los seres fabulosos

que se alimentan y procrean

en los confines del Imperio, muero hoy

bajo el puñal de mis esclavos.

He disfrutado del ocio, del placer

$y$ del dolor que me fueron dados.

Niego la inmortalidad del alma, creencia

pregonada por necios seguidores

de un hombre de la Palestina.

No existe el alma, no existe premio

ni castigo. Miserable el que imagine

una vida futura. Infeliz quien cree

en estos designios y hace proyectos,

abandonando para siempre este reino,

el dulce asombro entre las cosas. 
Polvo he sido y en polvo

me convertiré en unos momentos

cuando la furia del Vesubio nos alcance. ${ }^{20}$

El elemento exótico es en Cantigas otro ingrediente importante para construir la alteridad, y se reconoce casi siempre por sus marcas toponímicas: Alejandría, Nairobi, Kalahari. Pero el procedimiento más característico del libro, y el que lo distingue realmente de los otros considerados, es la utilización del humor. Si la parodia, en el sentido bajtiniano del término, remite a un proceso de inversión que puede producir la risa irónica o sarcástica, la risa inteligente o la risa procaz, Almela ha experimentado con ella hasta lograr momentos contundentes como en "Lamento en el Monasterio de San Pedro de Cardeña", donde el título y el epígrafe ("Ya lo veo que estades vos en ida / e nos de vos partir nos hemos en vida.") reenvían al supuesto emisario de ese poema que es, en realidad, la letra de una canción popular. El momento dramático del Cantar del Mio Cid que el texto alude - la famosa despedida de su mujer y de sus hijas en Cardeña- es rápidamente parodiado, desdramatizado con la inclusión del tema popular lleno de elementos que bordean el estereotipo y la cursilería. La yuxtaposición entre título, epígrafe y canción crean, pues, un efecto global de indudable efectividad:

\author{
Cuando tú te hayas ido \\ con mi dolor, a solas, \\ evocaré el idilio \\ de las azules olas. \\ Cuando tú te hayas ido \\ me envolverán las sombras. ${ }^{21}$
}

Todos estos procedimientos de enmascaramiento y simulación de la voz podrían considerarse como ejercicios preparatorios, como muestra miscelánea de destrezas, antes de acometer el trabajo expuesto en la segunda parte, "Cantigas". Esta segunda parte se abre con un epígrafe que, paradójicamente, no proviene de ninguna muestra de las numerosas cantigas medievales, sino de un texto aparentemente extraído de la Antología Palatina: "¡Ah, Deseos, por vuestra Madre Citerea, / quemad, quemad a la niña rebelde y obligadle / a que, por fin, no niegue que ama!". Y sin embargo, en esta cita está contenido quizás lo esencial de la "cantiga de amigo" que, a mi modo de ver, interactúa a lo largo de toda la sección por el solo influjo del título, el cual invita a leer los poemas en función del modelo de esa forma peculiar de la tradición galaico-portuguesa medieval basada en la expresión amorosa de un personaje femenino. Y en eso precisamente es que "Cantigas" consiste: ya no la diversidad miscelánea de las máscaras anteriores, sino una sola máscara y una sola voz que ponen en escena la experiencia amorosa de una mujer sin nombre, a veces reconocida como tal por marcas autorreferenciales ("Yo, la aprendiz, te merezco."), otras por la marca masculina del destinatario (" $¿ Q u e ́$ has hecho, amado, / sin mi boca?"), pero principalmente

\footnotetext{
${ }^{20}$ Harry Almela 15.

${ }^{21}$ Harry Almeda 22.
} 
por las constantes alusiones perifrásticas del acto amoroso y a la señalización de los dos papeles diferenciables que juegan en él la amante y el amado ("Hunde tus manos en mi pozo, / Clava los garfios sobre / esta madera. ...", "No sabe cuánto amo / su peso en mis redes.")

La imagen de la mujer que estos poemas ponen en evidencia se vincula, sin duda, con las respectivas imágenes que surgen en Fatal y en Toledana. Por un lado, hay claras alusiones a la posición de la mujer medieval en el orden amoroso. Por el otro, hay una imagen que, sin presentarse en tono marcadamente reivindicatorio de la posición de la mujer en el intercambio amoroso, transmite cierta posición privilegiada, dominadora, de su papel en ese intercambio, haciendo recordar las máscaras características de la mujer en Fatal:

\author{
Hilas el lienzo. Te dejo \\ hacer. Crees demasiado \\ en mi inocencia. No conoces \\ los secretos de mi guerra. \\ Miro distraída los rincones, \\ el trozo de luz que te enmascara. \\ No sabes de este territorio, del \\ hilo transparente que \\ me engraza. Del cenital \\ de mi vientre.
}

Mi cuerpo te entretiene. Yo te gozo. ${ }^{22}$

Como Toledana, Diario de John Roberton se inicia con una nota firmada por la autora que sitúa, de entrada, el horizonte histórico y documental en relación con el cual el poema se proyecta y se construye. La nota es larga y está llena de precisiones de carácter cronológico, biográfico y bibliográfico que dan las claves de la existencia de un referente real y de un texto anterior - "prototexto" y "pretexto" al mismo tiempo- del cual el poemario es una reescritura en clave lírica: "El doctor J. H. Roberton, escocés de nacimiento, llegó a Angostura - hoy Ciudad Bolívar- en 1818 y murió en 1820, en la misma ciudad ... Hombre sensible, aunque limitado por los prejuicios de su sociedad, de sólida formación científica y cultural y heredero, al fin de una tradición de conquistadores y aventureros proclives a la literatura, dejó un testimonio escrito: Journal of an Expedition 1400 miles up the Orinoco and 300 up the Arauca (Londres, 1822)." Lo que más nos importa de esa nota, sin embargo, son los fragmentos que explicitan, en cierto modo, la poética del libro, su mecánica y su método. Citaré dos; en el primero Strepponi se refiere a las fuentes documentales de su investigación y muestra el tipo de trabajo efectuado sobre esos materiales previos —cita, glosa, invención: "Tomé literalmente de su diario largos pasajes. Algunos detalles fueron extraídos de crónicas de la época. Las cartas son de mi entera invención.

\footnotetext{
${ }^{22}$ Harry Almeda 65.
} 
En cuanto a la idea del exilio de Dios como origen del mal, proviene de los cabalistas judíos del siglo XVI." En el segundo, aludiendo a Eliot, marca su proyecto con la deliberada confusión de máscaras y de voces que ya hemos visto caracterizando a los tres poemarios anteriores: "Confieso haber alcanzado una confusión notable y desconocida para mí en este particular proceso de escritura que comenzó en 1818 y en el que participaron tres autores. Pensaba entonces en T. S. Eliot, por supuesto, y en que toda verdad literaria, aun si dolorosa, es artificio".

Así, pues, desde el comienzo Strepponi pone las cartas sobre la mesa, colocando su trabajo en la ambigua zona fronteriza en que se tocan, en cierta literatura, lo documental y lo imaginario, sin ningún interés por su parte en resolver semejante ambigüedad, ya que, sin duda alguna, el libro se define en función de ese juego abierto de la duplicidad de identidades, del enmascaramiento y la simulación. Todo ello sirve de soporte a la representación del problema que realmente le interesa a Strepponi: el de la experiencia radical del mal. El Diario de John Robertson, el real y el imaginado, el lleno de detalles descriptivos y el interpolado con evocaciones de la mística judía, funciona, en su duplicidad, como "pretexto" y "prototexto" de esa aventura literaria en el territorio metafísico del mal que corroboraría el "exilio de Dios". Los epígrafes, por su parte, no hacen sino reforzar este proceso, y cito sólo uno de los tres, el de Henri Irénée Marrou: "El Demonio es un Ángel y, pese a su caída, conserva los privilegios de su naturaleza intacta, en la que siempre se transparenta la grandeza original ... es ese ser libre que, antes que ningún otro, eligió alejarse de la fuente de todo ser y acercarse a la nada de la que había sido sacado".

Definidos así su proyecto y sus principales procedimientos constructivos, vemos cómo el libro se inscribe en la misma órbita en la que giran los anteriores que hemos considerado: voluntad de extrañación, voluntad de construir una alteridad que suplante, primero, la realidad inmediata, presente, por otra exótica y anacrónica, y, segundo, la propia identidad, por una identidad asumida, fingida, apócrifa.

Para simular la voz de Robertson, Strepponi no sólo recurre a la cita directa (transcripción literal de partes del diario original), sino a la glosa (versiones del mismo diario), al discurso supuesto (lo que hubiera podido pensar, decir, escribir el personaje histórico) y a la mera imaginación (cartas inventadas, suenos). Todos estos procedimientos de relación intertextual se muestran en el poemario como dos bloques discursivos yuxtapuestos: por un lado los fragmentos literales del diario y por otro la reescritura del mismo a través de todos los mecanismos de parodización descritos, surgiendo de esa interacción el tono general de fría objetividad que parece animar a todo el conjunto. Un buen ejemplo sería el poema correspondiente al " 1 ' de enero de 1819 ":

Las tropas que esperamos no están aquí sino en el Palmar.

Damos marcha atrás.

Las tropas no llegan.

Ya es de noche.

No son 1200 los hombres del general Monagas, sino 400 soldados desnudos y 50 ingleses bajo el mando de Rooke. 


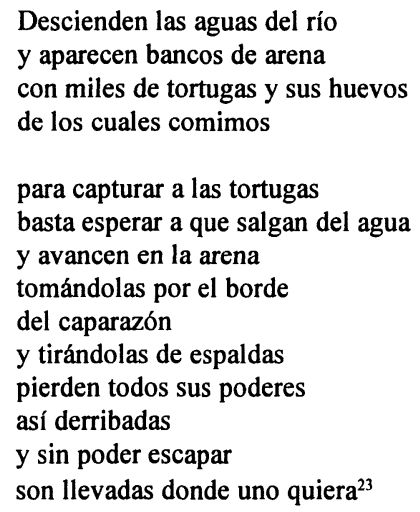

La casi completa ausencia de imágenes, la enunciación descriptiva sin apenas adjetivación, los detalles de carácter documental expuestos sin intermediación provenientes de un diario escrito más en la perspectiva de un mensaje oficial que en la de un registro moroso de la propia intimidad - colaboran para sostener una atmósfera discursiva ajena a toda exageración mistificante del personaje y de su aventura. La experiencia terrible del mal es representada, de este modo, de manera sutil pero eficaz. Sabiamente dosificado, un creciente número de pequeños detalles indiciales - geográficos o climáticos, biológicos, anatómicos, bélicos, médicos, oníricos- se acumulan para producir una contundente, aunque dispersa, imagen del mal como absoluto. Lo exótico mismo del paisaje selvático guayanés, la despiadada y sangrienta condición de la guerra, las bestias, los ríos gigantescos, las enfermedades desconocidas, las pesadillas, el hambre, van configurando, a medida que la máscara de Roberton nos habla fríamente, el retrato de esa experiencia límite, de ese real descenso a los infiernos en que consiste su aventura dramática.

Para construir su "efecto de alteridad", Strepponi tupe ciertamente su escritura, con minuciosidad casi científica - y este sería otro de los intertextos posibles- de datos proporcionados por el ojo observador de un médico que analiza y describe lo que ve con pasmosa sangre fría - en lo que habría percibir, en realidad, la prueba misma de la implacable indiferencia del mal: datos bélicos - número de soldados, nombres de generales, batallones y barcos; datos técnicos - cómo se decapita a alguien, cómo se mata una res, la receta para hacer tasajo; datos ambientales - incendios, cocodrilos devorando a un hombre, el inagotable ruido diabólico de la selva; pero lo que hace realmente coherente ese efecto es la mínima perturbación que, sobre toda la exposición de esos detalles, ejerce la descomposición lírica del texto, descomposición que pareciera limitarse a reescribir en verso el texto original, quebrando levemente la dureza del discurso de Roberton mediante el empleo del espaciamiento interestrófico, o mediante la interpolación de discursos tomados de otras fuentes y de carácter más lírico que el resto.

\footnotetext{
${ }^{23}$ Blanca Strepponi 17.
} 
Texto de una serenidad sorprendente - nada de exclamaciones ni de hipérboles: las situaciones más crueles o sangrientas son exhibidas con la pulcritud y precisión de un cirujano-Diario de John Robertson logra hacernos creer, por momentos, que en verdad escuchamos la voz de ese médico escocés seducido por la idea de la libertad y por el mundo salvaje de la América del Sur a principios del siglo XIX. Y, en ese sentido, es, tal vez, el libro que con mayor eficacia, entre los aquí considerados, cumple con su proyecto de alteridad.

A la luz de los elementos de juicio capturados en el camino de una lectura rasante y provisional de estos cuatro libros, podemos concluir celebrando la alternativa que proponen para el trabajo poético en la literatura venezolana de los noventa. Una alternativa que, además de los rasgos caracterizadores antes señalados, nos pone en la pista de un nuevo tipo de poeta: la del poeta cada vez menos silvestre o espontáneo, que construye sus mundos imaginarios a través de procedimientos eruditos, que investiga, que interactúa con otros textos de su tradición y que se atreve a jugar con ellos, aplicándoles todas las estrategias de la simulación y el enmascaramiento, de la parodia y la ironización, afirmando así, me parece, esa propensión a fundar una alteridad lúdica en el poema que nos promete, quién sabe, un buen número de experiencias de alteración de la autoría, la identidad, la solemnidad - y otras arrogancias - en nuestra inmediata y próxima poesía. 